\title{
Depersonalization Disorder
}

National Cancer Institute

\section{Source}

National Cancer Institute. Depersonalization Disorder. NCI Thesaurus. Code C94331.

A disorder characterized by persistent or recurrent episodes of feeling detached from one's self (either one's body or one's mental processes), although the sufferer remains aware that this is only a feeling and does not represent reality. 